1125 EFFICACY OF AN INDIVIDUALIZED STRATEGY FOR THE PHARMACOLOGICAL CLOSURE OF PDA WITH IBUPROFEN IN PRETERM INFANTS: EVALUATION BY ECHOCARDIOGRAPHY

doi:10.1136/archdischild-2012-302724.1125

S Galletti, A Cosentino, A Malavolti, E Machtey, G Faldella. Neonatology and Intensive Care Unit - Sant'Orsola-Malpighi Hospital - University of Bologna, Bologna, Italy

Background and Aims The aim of study is to evaluate the applicability of an individualized strategy for closure of PDA in preterms. We verified the closure rate and consequently the failure of PDA closure, the rate of reopening and the onset of secondary outcomes.

Methods We recruited 36 preterms (27 weeks mean GA; mean birth weight $828 \mathrm{~g}$ ) with PDA and candidates for the pharmacological closure according to the internal protocol.

Using serial ECHOS, we evaluated the persistence of the PDA after the administration of a first dose of ibuprofen, establishing the need to repeat a second or third dose each 24 hours.

Results We observed a rate of complete closure of $77.7 \%(33.3 \%$ after the first dose, $30.5 \%$ after the second and $13.8 \%$ after the third dose).

The incidence of re-opening is $16.6 \%$, without significant difference related to the number of doses $(\mathrm{p}=1)$.

There was a significant difference in terms of birth weight and GA between patients with persistent PDA (mean BW $485 \mathrm{~g}$ and mean GA 24+3) and patients who kept the ductus closed (mean BW $901.4 \mathrm{~g}$ and GA 27) $(\mathrm{p}<0.05)$.

There was no significant difference in terms of incidence of outcomes (IVH, NEC, broncodisplasia, deaths) comparing to a group which received a standard treatment of 3 doses.

Conclusion The individualized strategy allows to expose preterms to a minor amount of doses, without changing the number of closure and outcomes.

However, the extreme GA are associated with an increased risk of failure of closure and reopening.

\section{VITAMIN D LEVELS AND MYOCARDIAL FUNCTION IN PRETERM INFANTS}

doi:10.1136/archdischild-2012-302724.1126

1,2,3K Armstrong, ${ }^{4} \mathrm{C}$ Onwunmeme, ${ }^{5} \mathrm{O}$ Franklin, ${ }^{1,2,6 \mathrm{E}}$ Molloy. ${ }^{1}$ National Children's Research Centre, National Children's Research Centre; ${ }^{2}$ Neonatology, National Maternity Hospital; ${ }^{3}$ Cardiology, Our Lady's Children's Hospital; ${ }^{4}$ University College Dublin; ${ }^{5}$ Cardiology, Our Lady's Children's Hospital Crumlin Dublin 12; 'Paediatrics, University College Dublin, Dublin, Ireland

Bakground Low Vitamin D levels have been linked to cardiac failure in the adults and children. Tissue Doppler Imaging (TDI) is evolving as a superior measure of subtle changes in myocardial contractility in preterm infants. We aimed to correlate Vitamin D levels at birth with TDI measures of systolic and diastolic function.

Methods Preterm infants $<32$ weeks gestation were recruited. Vitamin D levels were measured at birth and echocardiography was carried out on Day 1. TDI myocardial velocities were recorded using a pulsed wave doppler sample from the lateral left/right ventricular wall \& intraventricular septum. Peak systolic (S'), early diastolic (E') and late diastolic $\left(\mathrm{A}^{\prime}\right)$ velocities were recorded.

Results Ten preterm infants with structurally normal hearts were recruited. Mean (SD) gestational age was 28 (1.7) weeks and birthweight $1.29(0.3) \mathrm{kg}$. There was no significant increase in Right ventricular systolic $(5.1 \mathrm{~cm} / \mathrm{sec}$ vs $4.8 \mathrm{~cm} / \mathrm{sec})$ or diastolic myocardial velocity measures $(5.2 \mathrm{~cm} / \mathrm{sec}$ vs $5.1 \mathrm{~cm} / \mathrm{sec})$ or left myocardial velocity systolic $(3.7 \mathrm{~cm} / \mathrm{sec}$ vs $3.9 \mathrm{~cm} / \mathrm{sec})$ or diastolic $(4.1 \mathrm{~cm} / \mathrm{sec}$ vs $4.0 \mathrm{~cm} / \mathrm{sec})$ measures between those with severe Vitamin $D$ deficiency $(<30 \mathrm{nmol} / \mathrm{L})$ and those with low normal levels of Vitamin D.
Conclusion Neonates with severe Vitamin D deficiency have similar TDI measures of systolic and diastolic velocity to those with near normal levels. In our small cohort severe Vitamin D deficiency appears to cause no impairment in myocardial contractility.

\section{MEASURING BLOOD PRESSURE AND MANAGING "HYPOTENSION" IN NEWBORN BABIES: VARIATION IN PRACTICES}

doi:10.1136/archdischild-2012-302724.1127

S Garg, W Tin. Neonatal Medicine, South Tees Hospitals NHS Foundation Trust, Middlesbrough, UK

Background and Aims Measuring blood pressure (BP) is an important part of cardiovascular assessment in newborns. Although arterial BP is considered as a gold standard, various methods of noninvasive $\mathrm{BP}$ measurements are used in clinical practice. The various studies have shown that BP measured by Doppler is better correlated with arterial BP than the oscillometric method. Regardless of definition of "hypotension", there is no agreement on its management strategies.

The Aim of this study is to survey the variations in practices in all tertiary neonatal units across England in management of hypotension.

Methods A structured questionnaire based telephonic survey. Results The response rate was 100\% (45 units surveyed). Forty units (89\%) use arterial BP and/or oscillometric method, and only 5 units $(11 \%)$ use Doppler method. Twenty seven units (60\%) have written guidelines on management of hypotension. Forty $(90 \%)$ units use fluid bolus as the first line management; two units use fresh frozen plasma if the perfusion remains low. Thirty seven units $(82 \%)$ use dopamine as the first line inotropic agent. Twenty units (45\%) keep the umbilical arterial lines for as long as needed but the others keep them for different periods (3-14 days).

There are 9 different makes of oscillometric monitors used, and $10 \%$ of the units use different makes in one intensive care area.

Conclusion Marked variation remains in management of hypotension in newborn babies. There is a need to formulate evidence based guidelines for management of hypotension and to study the accuracy of non-invasive methods of BP measurement.

\section{EVALUATION OF ORAL PROSTAGLANDIN E1 IN MANAGEMENT OF DUCTUS DEPENDENT CONGENITAL HEART DISEASE}

doi:10.1136/archdischild-2012-302724.1128

${ }^{1}$ A Annagür, ${ }^{2 H}$ Altunhan, ${ }^{3} \mathrm{M}$ Konak, ${ }^{4} \mathrm{~S}$ Karaaslan, ${ }^{3} \mathrm{R}$ Örs. ${ }^{1}$ Selcuk University, Selcuklu Medical Faculty, Department of Neonatology; ${ }^{2}$ Abant Izzet Baysal University, Medical Faculty, Department of Neonatology; ${ }^{3}$ Konya University, Meram Medical Faculty, Department of Neonatology; ${ }^{4}$ Konya University, Meram Medical Faculty, Department of Cardiology, Konya, Turkey

Introduction Intravenous prostaglandin E1 (PGE1) infusion is a treatment which effect is proven in ductus dependent congenital heart disease. However, PGE1 is very expensive, needed continuous infusion and its supply is difficult by every center. When its long term use is necessary, these problems become more important.

Aim To show whether oral PGE1could keep the ductus open or not till the supply of intravenous PGE1.

Method Ten patients, who were admitted to newborn intensive care unit with the diagnosis of ductus dependent congenital heart disease and received oral PGE1 till the supply of intravenous PGE1, were evaluated.

Results It was observed that the $\mathrm{PO} 2$ and $\mathrm{SO} 2$ levels of patients measured 2 hours after the initiation of oral PGE1 were significantly increased compared to the levels before initiation of PGE1 $(p<0.05)$. It was also observed that the $\mathrm{PO} 2$ and $\mathrm{SO} 2$ levels of patients 
measured 2 hours after the initiation of intravenous PGE1 were slightly increased compared to levels before initiation of intravenous PGE1 ( $\mathrm{p}<0.05)$.

Discussion Although intravenous PGE1 is more effective than oral PGE1 in short term usage, oral PGE1 is also sufficiently effective in keeping the dustus open. For this reason until the intravenous PGE1 is supplied oral PGE1 may be used as an alternative treatment choice. We think that in long term use oral PGE1, which is cheaper and easy to use, could be used instead of intravenous PGE1 without need of admission to hospital and opening intravenous line.

\section{SURGICAL TREATMENT OF PATENT DUCTUS ARTERIOSUS IN PRETERM INFANTS. TEN-YEAR EXPERIENCE WITH LIGATION IN THE NEWBORN INTENSIVE CARE UNIT}

doi:10.1136/archdischild-2012-302724.1129

S Galletti, A Cosentino, A Malavolti, E Macthey, G Faldella. Neonatology and Intensive Care Unit - Sant'Orsola-Malpighi Hospital - University of Bologna, Bologna, Italy

Background and Aim of study Frequently in low-birth-weight infants, ductus arteriosus fails to close spontaneously. This study evaluates the results of surgical ligation of symptomatic PDA in low birth weights preterms.

Methods We reviewed the medical records of all infants undergoing surgical closure of PDA from 2000 to 2010. Demographic data, weight at operation, respiratory assistance pre-operatory, surgical technique to close PDA and outcome were analyzed.

Results Thirty infants underwent surgical closure of PDA in which either indomethacin or ibuprofen treatment had failed or was contraindicated. The mean GA was 27 and the mean birth weight was $752 \mathrm{~g}$. The average weight at operation was $790.5 \mathrm{~g}$. PDA was surgically closed by left thoracotomy using hemoclips.

Postoperative complication occurred in 4 patients, which included intraoperative bleeding (1), pneumothorax (1), lymphatic leak (2). No vocal cord paralysis nor diaphragmatic paralysis were observed. We also registered outcomes related to PDA: broncodisplasia (22), IVH(8), NEC(8), ROP(13). There was no mortality related to surgery.

Conclusion We conclude that surgical closure of hemodynamically significant PDA is safe and effective in preterm low birth weights infants when pharmacological treatment is ineffective or contraindicated. The associated morbidity is minimal and no surgery-related mortality was observed.

\section{EVALUATION OF THE NEONATES WITH CYANOTIC CONGENITAL HEART DEFECTS HOSPITALIZED IN A NICU AT SIX YEARS PERIOD}

doi:10.1136/archdischild-2012-302724.1130

'F Özlü, 'M Satar, ${ }^{2 N}$ Özbarlas, 'H Yapıcıoğlu, 'N Narlı, 'E Kale Çekinmez, 'K Mert. ${ }^{1}$ Neonatology; ${ }^{2}$ Pediatric Cardiology, Çukurova University, Adana, Turkey

Severe congenital heart defects might be symptom free in first days of life. Therefore only half of the congenital heart defects were diagnosed in neonatal period.

In six years period, 86 neonates with the diagnosis of cyanotic congenital heart defects out of 3672 neonates hospitalized in our unit were evaluated. Neonates with the diagnosis of Down syndrome, trisomies and major congenital defects other than heart were excluded from the evaluation. Mean gestational weeks and birth weights of the neonates were 39, 3 (35-40) week and 3128 (1770-4470) gr respectively. The most common pathology of the heart defects was transposition of great arteries (TGA) in 31 neonates $(\% 36)$ and the second common pathology was pulmonary atresia in 17 neonates $(\% 19,8)$. Four of the 31 neonates with TGA had arteriel switch operation and four of them had septostomy procedure, while 23 did not need any invasive procedure. Fourteen of 17 neonates with pulmonary atresia had central or peripheral shunt operations. $51,2 \%$ of the neonates were discharged while $12.8 \%$ of them were discharged due to request of the family. Three of the neonates who had arteriel switch operation and 11 neonates who had shunt operation were discharged.

Early recognition of infants with congenital heart disease that has high mortality and morbidity in neonatal period and implementation of early intervention in patients with ductus-dependent heart defects was considered to have a positive effect on prognosis.

\section{CARDIOVASCULAR AND HORMONAL RESPONSES TO HYPOXIC STRESS IN THE PRETERM PIGLET}

doi:10.1136/archdischild-2012-302724.1131

'YA Eiby, 'MP Staunton, 'LL Wright, 1'2ER Lumbers, 'PB Colditz, 'BE Lingwood. 'UO Centre for Clinical Research, The University of Queensland, Brisbane, OLD; ${ }^{2}$ Mothers and Babies Research Centre, Hunter Medical Research Institute, Newcastle, NSW, Australia

Background and Aims Immature control of the cardiovascular system may be a contributing factor to poor cardiovascular function and associated increases in mortality and morbidity in preterm infants. This study aimed to assess cardiovascular and hormonal responses to a mild hypoxic stress in newborn piglets.

Methods Piglets were delivered by C-section at 97 and 113 days of gestation (term $\approx 115 \mathrm{~d}$ ). An additional preterm group was exposed to maternal glucocorticoid treatment. Changes in mean arterial blood pressure (MAP), skin blood flow and plasma concentrations of adrenalin, noradrenalin, angiotensin II and cortisol were measured in response to acute hypoxia ( $4 \% \mathrm{O}_{2}$ for $20 \mathrm{~min}$ ).

Results Preterm piglets were less likely to exhibit a mature cardiovascular compensatory response to hypoxia (increased MAP and reduced skin blood flow) than term piglets. Plasma adrenalin and noradrenalin concentrations at the end of hypoxia were increased in all groups and were $2-3$ fold higher in preterm pigs than in term pigs $(\mathrm{P}<0.05)$. Plasma cortisol levels were increased at the end of hypoxia in term piglets $(\mathrm{P}<0.05)$ but not in preterm or glucocorticoid exposed preterm piglets. Angiotensin II levels were reduced in glucocorticoid exposed preterm piglets compared to untreated preterm piglets $(\mathrm{P}<0.05)$.

Conclusions The reduced cardiovascular compensatory response to hypoxia in preterm pigs is not the result of reduced plasma levels of catecholamines during hypoxia. Low levels of angiotensin II in glucocorticoid exposed preterm piglets may contribute to poor control of skin blood flow during hypoxia.

\section{THE EFFECT OF PLATELET COUNT ON SUCCESSFUL MEDICAL CLOSURE OF PATENT DUCTUS ARTERIOSUS}

doi:10.1136/archdischild-2012-302724.1132

P Nath, M Avondo, R Roy. Neonatal Unit, Norfolk and Norwich University Hospital NHS Trust, Norwich, UK

Background and Aim Patent Ductus Arteriosus (PDA) is a shunt vessel connecting the pulmonary artery and the aorta. It usually closes after birth, but persistence of PDA in preterm neonates is a major cause of morbidity and mortality. A recent study suggested that platelet counts are likely to contribute to PDA closure in humans.

We aim to investigate relationship between platelet counts and closure of PDA after medical treatment with Indomethacin or I buprofen.

Methods All preterm infants born $\leq 32$ weeks and birth weight $\leq 1500$ grams born between 01 January 2008 and 31 December 2010 were included. Retrospective data was collected from the case records, SEND neonatal database and laboratory result systems. 